\title{
Inhibition of Mild Steel Corrosion by some Phenyltetrazole Substituted Compounds in Hydrochloric Acid
}

\author{
Y. Elkacimi, ${ }^{a}$ M. Achnin, ${ }^{c}$ Y. Aouine, ${ }^{b}$ M. Ebn Touhami, ${ }^{a, *}$ A. Alami, ${ }^{b}$ \\ R. Touir, ${ }^{a}$ M. Sfaira, ${ }^{c}$ D. Chebabe, ${ }^{a}$ A. Elachqar, ${ }^{b}$ B. Hammouti ${ }^{d}$ \\ ${ }^{a}$ Laboratory of Materials, Electrochemistry and Environment, Faculty of Sciences, University Ibn Tofail, \\ BP. 133 - 14000, Kénitra, Morocco \\ ${ }^{b}$ Laboratory of Organic Chemistry, Faculty of Sciences Dhar El Mahraz, Sidi Mohammed Ben Abdellah \\ University, BP 1796 - 30000, Atlas - Fez, Morocco \\ ${ }^{c}$ Laboratory of Materials Engineering, Modelling and Environment, Faculty of Sciences Dhar El \\ Mahraz, Sidi Mohammed Ben Abdellah University, BP 1796 - 30000, Atlas - Fez, Morocco \\ ${ }^{d}$ LCAE-URAC18, Faculty of Sciences, Mohammed the $1^{\text {st }}$ University, \\ BP 717 - 60000, Oujda, Morocco
}

Received 18 April 2011; accepted 28 February 2012

\begin{abstract}
Phenyltetrazole substituted compounds, namely 5-phenyl-1H-tetrazole (PT), 5-(4chlorophenyl)-1H-tetrazole (Cl-PT), 5-(4-methoxyphenyl)-1H-tetrazole (MO-PT) and 5-p-tolyl-1H-tetrazole (M-PT) were synthesized to study their inhibition behavior on mild steel in $1 \mathrm{M} \mathrm{HCl}$ by weight loss measurement, potentiodynamic polarization studies and electrochemical impedance spectroscopy (EIS). It has been observed that corrosion rate decreases and inhibition efficiency increases with increasing in phenyltetrazole substituted concentration and dependence on molecular structure. Polarization data indicate that these compounds act as very good cathodic inhibitors of mild steel in $1 \mathrm{M} \mathrm{HCl}$. The result showed that the inhibition efficiency decreased with temperature and increased with immersion time. EIS has the same trend of inhibitive effect as that of the polarization data, which indicates the formation of a protective layer on mild steel surface by molecules adsorption.
\end{abstract}

Keywords: corrosion, inhibition, phenyltetrazole, mild steel, acid medium, potentiodynamic polarization, EIS.

\section{Introduction}

Mild steel is one of the major construction materials, which is extensively used in chemical and allied industries for the handling of acid, alkali and salt solutions $[1,2]$. Hydrochloric acid is the most difficult of the common acids to handle from

\footnotetext{
*Corresponding author. E-mail: mebntouhami@yahoo.fr
} 
the standpoints of corrosion and materials of constructions [3]. Inhibitors are widely used for protection of metals from corrosion in acid environments. So selecting the appropriate inhibitor for a particular metal is very important $[4,5]$. As acidic media $\mathrm{HCl}$ and $\mathrm{H}_{2} \mathrm{SO}_{4}$ are generally used in the treatment of steel and ferrous alloys, the corrosion inhibition of mild steel in acid media in general and in hydrochloric acid in particular has been reviewed [6].

Most of the well known inhibitors are organic compounds containing nitrogen [713], oxygen [9, 11-13] or nitrogen and sulfur [14,16] in their functional groups. Some studies have shown that the inhibition of the corrosion process is mainly decided by the formation of donor-acceptor surface complexes between free or $\pi$ electrons of an inhibitor and vacant d orbital of a metal [17-19].

The aim of this work is to evaluate and to compare the corrosion inhibition efficiency of some phenyltetrazole substituted compounds for mild steel in $1 \mathrm{M}$ $\mathrm{HCl}$ at $25{ }^{\circ} \mathrm{C}$ using weight loss measurement, potentiodynamic polarization and electrochemical impedance spectroscopy.

\section{Experimental}

\section{Material preparation}

Mild steel strips composed of: (wt.\%) $\mathrm{C}=0.11, \mathrm{Si}=0.24, \mathrm{Mn}=0.47, \mathrm{Cr}=0.12$, $\mathrm{Mo}=0.02, \mathrm{Ni}=0.1, \mathrm{Al}=0.03, \mathrm{Cu}=0.14, \mathrm{~W}=0.06, \mathrm{Co}<0.0012, \mathrm{~V}<0.003$ and rest $\mathrm{Fe}$ were used. For weight loss measurements, mild steel strips with a surface area of $4 \mathrm{~cm}^{2}$ were used. For potentiodynamic polarization and electrochemical impedance spectroscopy, mild steel strips with an exposed area of $1 \mathrm{~cm}^{2}$ were used.

Mild steel specimens were polished mechanically with emery papers of 100 to 1200 grades. They were subsequently degreased with acetone, washed and dried. An analytical reagent-grade $\mathrm{HCl}$ was used for preparing solutions. Corrosion inhibitors used are organic compounds synthesized in the laboratory [20-21]. The structural formulae of these inhibitors are shown in Fig. 1.

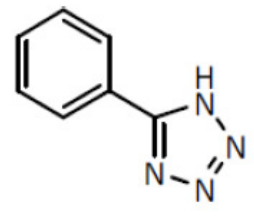

(a)

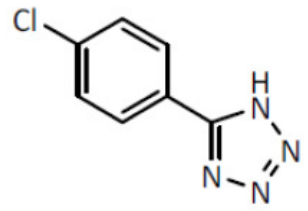

(b)<smiles>COc1ccc(-c2nnn[nH]2)cc1</smiles>

(c)<smiles>Cc1ccc(-c2nnn[nH]2)cc1</smiles>

(d)

Figure 1. Chemical formulae of the compounds used, (a): 5-phenyl-1H-tetrazole (PT), (b): 5-(4-chlorophenyl)-1H-tetrazole (Cl-PT), (c): 5-(4-methoxyphenyl)-1H-tetrazole (MO-PT) and (d): 5-p-tolyl-1H-tetrazole (M-PT).

\section{Weight loss measurement}

Weight loss experiments were done according to ASTM methods described previously [22, 23]. Tests were conducted in $1 \mathrm{M} \mathrm{HCl}$ for $6 \mathrm{~h}$ at $25^{\circ} \mathrm{C}$. The weight loss average of three substrate sheets could be obtained. The inhibition 
efficiency (IE \%) of the inhibitors on the mild steel corrosion was calculated as follows:

$$
I E \%=\frac{\omega_{0}-\omega}{\omega_{0}} \times 100
$$

where $\omega_{0}$ and $\omega$ are the corrosion rates of mild steel without and with the inhibitor, respectively.

\section{Electrochemical measurements}

Electrochemical measurements were conducted in a conventional three-electrode cylindrical glass cell at $25{ }^{\circ} \mathrm{C}$ with a platinum counter electrode (CE) and a saturated calomel electrode (SCE) as the reference electrode. The working electrode (WE) was in the form of a square cut from mild steel embedded in epoxy resin of polytetrafluoroethylene (PTFE), so that the flat surface was the only surface in the electrolyte. The polarization curves were recorded by using a potentiostat/galvanostat (PGZ100). The potential increased with a speed of 1 $\mathrm{mV} / \mathrm{s}$ and started from potential of $-750 \mathrm{mV}$ to $-100 \mathrm{mV}$ vs. SCE. The IE\% was defined as:

$$
I E \%=\frac{i_{\text {corr }}^{0}-i_{\text {corr }}}{i_{\text {corr }}^{0}} \times 100
$$

where $i_{\text {corr }}^{0}$ and $i_{\text {corr }}$ are the corrosion current density values without and with inhibitor, respectively.

\section{EIS measurements}

The electrochemical impedance spectroscopy measurements were carried out using a potentiostat/galvanostat (PGZ100), with a small amplitude ac. signal (10 $\mathrm{mV} \mathrm{rms}$ ), over a frequency domain from $100 \mathrm{KHz}$ to $10 \mathrm{mHz}$ at $25{ }^{\circ} \mathrm{C}$. The results were then analysed in terms of equivalent electrical circuit using bouckamp program [24]. The inhibition efficiency of the inhibitor has been found from the relationship:

$$
I E \%=\frac{R_{c t}-R_{c t}^{0}}{R_{c t}} \times 100
$$

where $R_{c t}^{0}$ and $R_{c t}$ are the charge transfer resistance values in the absence and the presence of the inhibitor, respectively.

\section{Results and discussion}

\section{Weight loss studies}

The weight loss measurements were conducted in $1 \mathrm{M} \mathrm{HCl}$ at $25{ }^{\circ} \mathrm{C}$. The values of corrosion rate $\left(\omega_{\text {corr }}\right)$ at different concentrations of the used inhibitors are presented in Fig. 2. The results show that all the phenyltetrazole compounds act as effective corrosion inhibitors. The corrosion rate decreases with increasing the inhibitor concentration and following the order:

$$
\mathrm{PT}>\mathrm{M}-\mathrm{PT}>\mathrm{MO}-\mathrm{PT}>\mathrm{Cl}-\mathrm{PT}
$$


The difference in their inhibitive action can be explained by increasing of the effective electron density of the inhibitors by mesomeric effect in the case of ClPT, and by inductive effect in the case of M-PT [25]. In aromatic or heterocyclic ring compounds, the effective electron density at the functional group can be varied by introducing different substituent in the ring, leading to variations of the molecular structure.

The corrosion inhibition study indicated that Cl-PT and MO-PT have the highest IE\% compared to PT and M-PT. This can be attributed to the presence of chloride and oxygen atoms on the aromatic rings of Cl-PT and MO-PT, respectively.

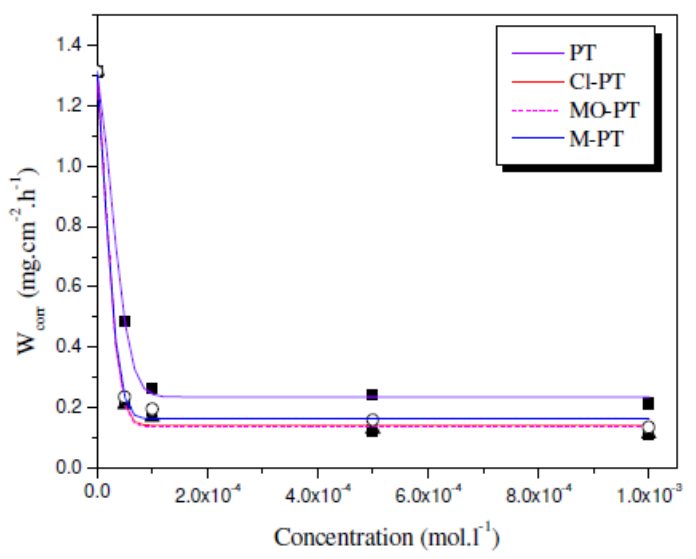

Figure 2. Corrosion rate obtained from weight loss measurements in $1 \mathrm{M} \mathrm{HCl}$ containing different concentrations of phenyltetrazole substituted compound.

\section{Potentiodynamic polarization studies}

The polarization behaviour of mild steel in $1 \mathrm{M} \mathrm{HCl}$ in the absence and presence of different concentrations of all phenyltetrazole is shown in Fig. 3-6.

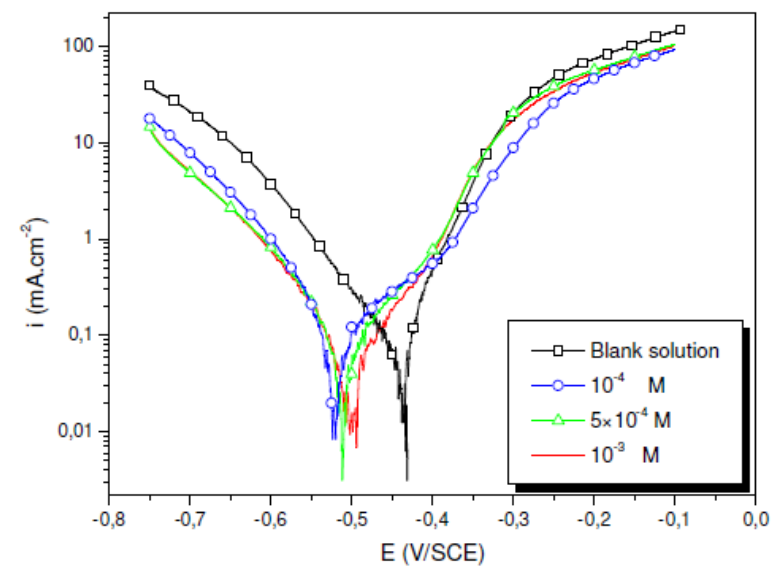

Figure 3. Potentiodynamic polarization curves for mild steel in $1 \mathrm{M} \mathrm{HCl}$ containing different concentrations of PT. 


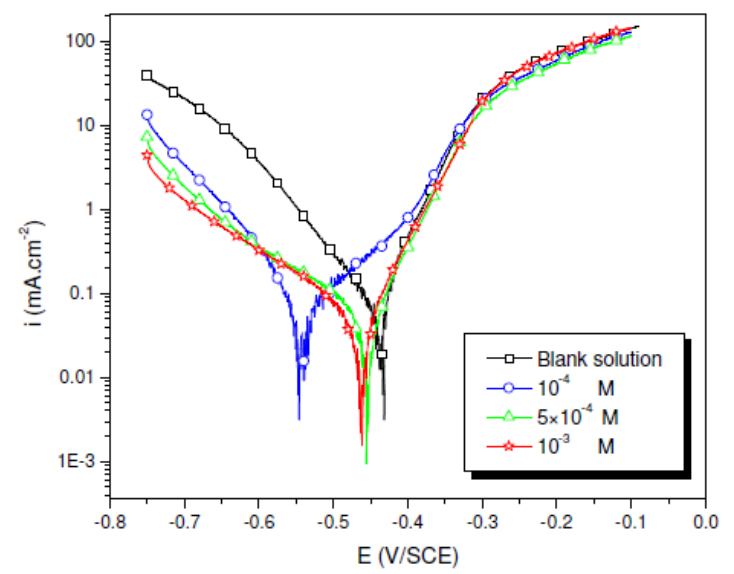

Figure 4. Potentiodynamic polarization curves for mild steel in $1 \mathrm{M} \mathrm{HCl}$ containing different concentrations of Cl-PT.

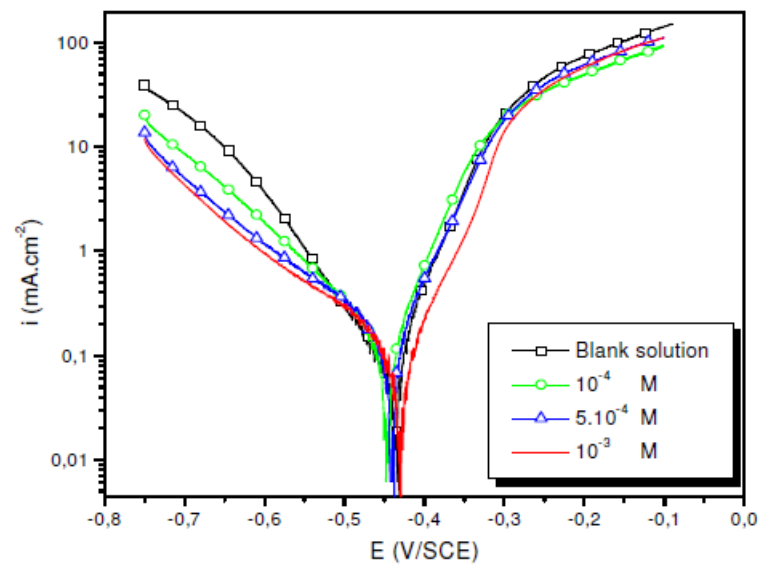

Figure 5. Potentiodynamic polarization curves for mild steel in $1 \mathrm{M} \mathrm{HCl}$ containing different concentrations of MO-PT.

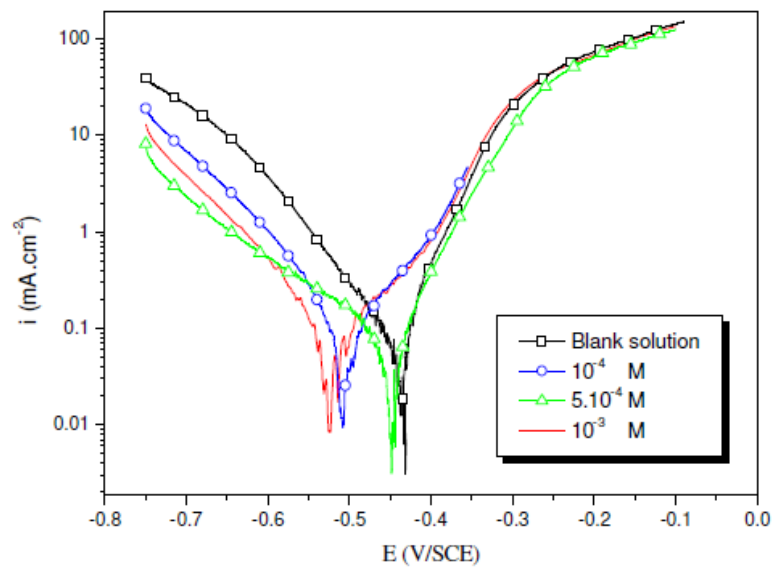

Figure 6. Potentiodynamic polarization curves for mild steel in $1 \mathrm{M} \mathrm{HCl}$ containing different concentrations of M-PT.

Electrochemical parameters such as corrosion current density $\left(i_{\text {corr }}\right)$, corrosion potential $\left(\mathrm{E}_{\mathrm{corr}}\right)$ and Tafel slope constants calculated from Tafel plots $\left(-\beta_{\mathrm{c}}\right)$ are given in Table 1 . These results show that all compounds bring down $\mathrm{i}_{\text {corr }}$ value at all concentrations and the maximum decrease is obtained at $10^{-3} \mathrm{M}$, suggesting that these compounds are effective corrosion inhibitors. Moreover, we note that 
these compounds cause a significant shift in $\mathrm{E}_{\mathrm{corr}}$ values, indicating that they are cathodic type inhibitors in $1 \mathrm{M} \mathrm{HCl}$.

It is apparent from the results that the IE\% of the Cl-PT is highest (93\%) among the compounds studied.

Table 1. Potentiodynamic electrochemical parameters obtained for mild steel in $1 \mathrm{M}$ $\mathrm{HCl}$ containing different concentrations of phenyltetrazole substituted compounds.

\begin{tabular}{|c|c|c|c|c|c|}
\hline Compounds & $\mathbf{C}(\mathbf{M})$ & $\mathbf{E}_{\text {corr }}(\mathbf{m V} / \mathbf{s c e})$ & $\mathbf{i}_{\text {corr }}\left(\boldsymbol{\mu} \mathbf{A} / \mathbf{c m}^{2}\right)$ & $\boldsymbol{\beta}_{\mathbf{c}}\left(\mathbf{m V} / \mathbf{d e c}^{-\mathbf{1}}\right)$ & $\mathbf{I E} \mathbf{( \% )}$ \\
\hline 1 M HCl & 00 & -432 & 470 & 156 & - \\
\hline \multirow{3}{*}{ PT } & $10^{-4}$ & -522 & 180 & 145 & 61 \\
& $5 \times 10^{-4}$ & -517 & 110 & 131 & 76 \\
& $10^{-3}$ & -492 & 94 & 133 & 80 \\
\hline \multirow{3}{*}{ Cl-PT } & $10^{-4}$ & -542 & 83 & 112 & 82 \\
& $5 \times 10^{-4}$ & -455 & 35 & 148 & 92 \\
& $10^{-3}$ & -462 & 34 & 169 & 93 \\
\hline \multirow{3}{*}{ MO-PT } & $10^{-4}$ & -446 & 124 & 128 & 73 \\
& $5 \times 10^{-4}$ & -438 & 117 & 158 & 75 \\
& $10^{-3}$ & -430 & 78 & 163 & 83 \\
\hline \multirow{2}{*}{ M-PT } & $10^{-4}$ & -510 & 115 & 122 & 76 \\
& $5 \times 10^{-4}$ & -447 & 98 & 125 & 79 \\
& $10^{-3}$ & -526 & 83 & 121 & 82 \\
\hline
\end{tabular}

\section{Electrochemical impedance spectroscopy (EIS) measurements}

Fig. 7-10 show Nyquist plots obtained from impedance measurements for mild steel in $1 \mathrm{M} \mathrm{HCl}$ in the presence of different concentrations of phenyltetrazole substituted compounds. A comparison between the measured and simulation data for the impedance plot of mild steel in $1 \mathrm{M} \mathrm{HCl}$ with and without $10^{-3} \mathrm{M}$ of $\mathrm{Cl}$ PT is shown in Fig. 11. It constitutes a good indication to prove the accuracy of the proposed circuit (Fig. 12) [26]. The various parameters such as chargetransfer resistance $\left(R_{\mathrm{ct}}\right)$ and double layer capacitance $\left(C_{\mathrm{dl}}\right)$ were obtained from impedance measurements and are shown in Table 2.

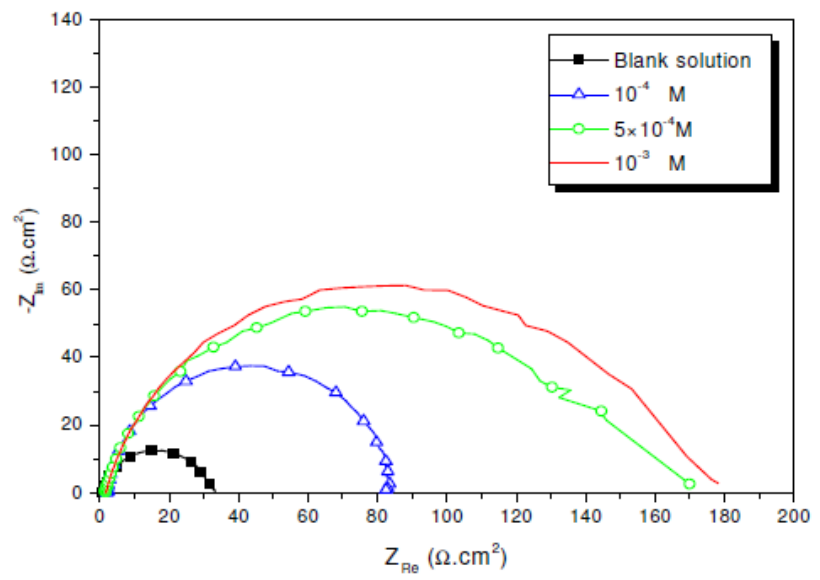

Figure 7. Nyquist plots for mild steel in $1 \mathrm{M} \mathrm{HCl}$ in the presence of different concentrations of PT over open circuit potential. 


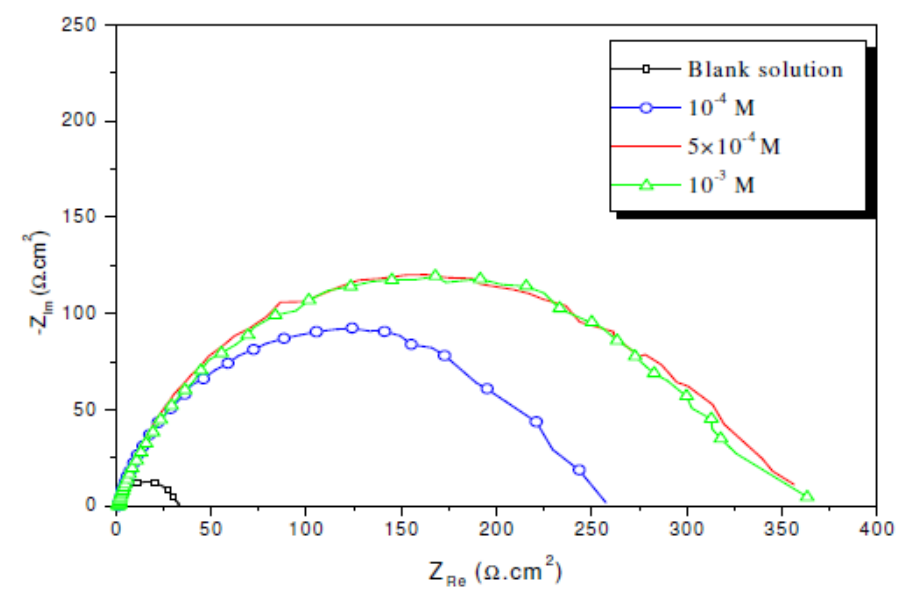

Figure 8. Nyquist plots for mild steel in $1 \mathrm{M} \mathrm{HCl}$ in the presence of different concentrations of Cl-PT over open circuit potential.

It is apparent from these plots that the impedance response of mild steel in uninhibited $1 \mathrm{M} \mathrm{HCl}$ solution has significantly changed after the addition of phenyltetrazole substituted compounds in the corrosive solution. This indicates that the impedance of inhibited substrate increases with increasing inhibitor concentrations and consequently the inhibition efficiency increases. The locus of the Nyquist plots was regarded as one part of a semicircle. The impedance diagrams obtained are not perfect semicircles and this difference has been attributed to frequency dispersion [27-28]. The greatest effect was observed at $10^{-3} \mathrm{M}$ of all compounds.

The addition of phenyltetrazole substituted to $\mathrm{HCl}$ is found to enhance $R_{\mathrm{ct}}$ values and bring down $C_{\mathrm{dl}}$ values. These observations clearly bring out the fact that the corrosion of mild steel in $1 \mathrm{M} \mathrm{HCl}$ is controlled by a charge transfer process and the corrosion inhibition occurs through the adsorption of the phenyltetrazole substituted compounds on mild steel surface. The decrease in the Cdl values can be attributed to the adsorption of inhibitors on metal surface [29].

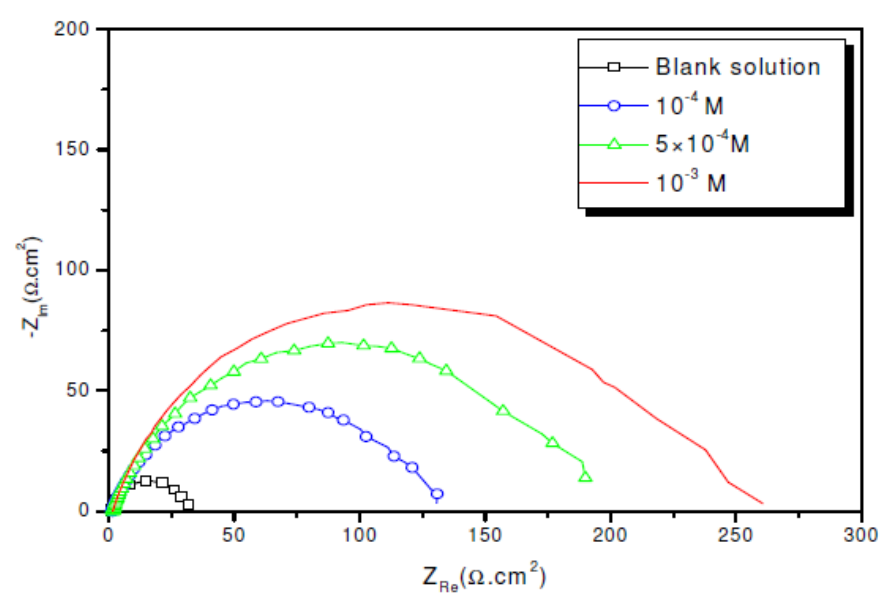

Figure 9. Nyquist plots for mild steel in $1 \mathrm{M} \mathrm{HCl}$ in the presence of different concentrations of MO-PT over open circuit potential. 


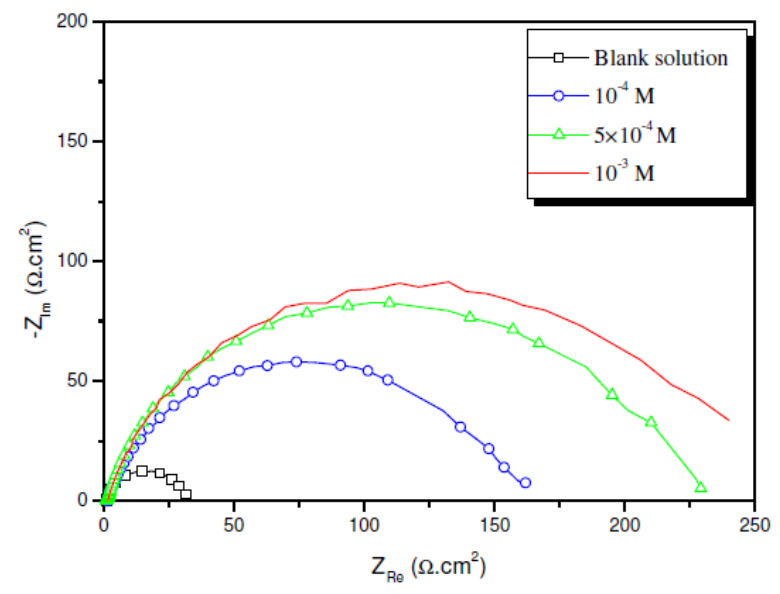

Figure 10. Nyquist plots for mild steel in $1 \mathrm{M} \mathrm{HCl}$ in the presence of different concentrations of M-PT over open circuit potential.

Values of corrosion inhibition efficiency obtained for various inhibitors follow the order: Cl-PT > MO-PT > M-PT > PT, which is in a good matching with results obtained from weight loss and polarization curve tests.

The effectiveness of a compound as corrosion inhibitor mainly depends on the size and the active centers of the compound [30]. The best performance of compounds Cl-PT and MO-PT as corrosion inhibitors over compound PT and MPT may be attributed to the presence of $-\mathrm{Cl}$ and $-\mathrm{OCH}_{3}$ groups in compound $\mathrm{Cl}-$ PT and MO-PT, respectively.

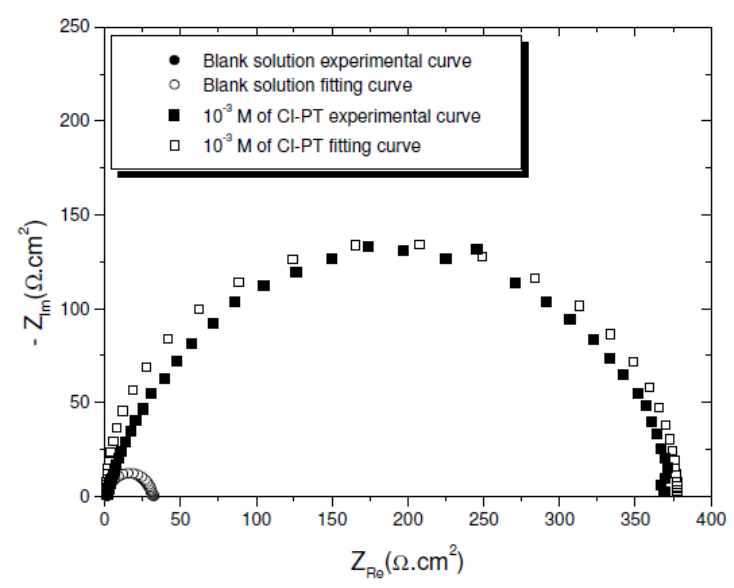

Figure 11. Experimental and fitting curves of Nyquist diagrams with and without $10^{-3}$ $\mathrm{M}$ of $\mathrm{Cl}-\mathrm{PT}$ for $1 \mathrm{~h}$ of immersion in $1 \mathrm{M} \mathrm{HCl}$.

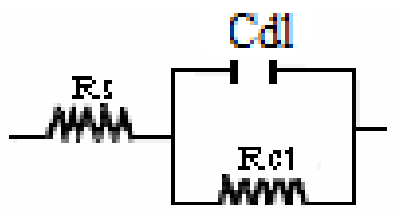

Figure 12. Equivalent circuit model for studied inhibitor: $R_{s}$ solution resistance, $R_{c t}$ charge-transfer resistance and $\mathrm{C}_{\mathrm{dl}}$ double layer capacitance. 
Table 2. Corrosion parameters obtained by impedance measurements for mild steel in 1 $\mathrm{M} \mathrm{HCl}$ at various concentrations of phenyltetrazole substituted compounds.

\begin{tabular}{|c|c|c|c|c|}
\hline Compounds & $\mathbf{C}(\mathbf{M})$ & $\mathbf{R}_{\mathbf{c t}}\left(\mathbf{\Omega . c m}^{2}\right)$ & $\mathbf{C}_{\mathbf{d l}}\left(\boldsymbol{\mu} \mathbf{F . c m}{ }^{-2}\right)$ & $\mathbf{I E ~ ( \% )}$ \\
\hline HCl 1 M & 00 & 32 & 160 & - \\
\hline \multirow{3}{*}{ PT } & $10^{-4}$ & 82 & 78 & 60 \\
& $5 \times 10^{-4}$ & 170 & 29 & 79 \\
& $10^{-3}$ & 184 & 26 & 82 \\
\hline \multirow{3}{*}{ Cl-PT } & $10^{-4}$ & 258 & 74 & 87 \\
& $5 \times 10^{-4}$ & 362 & 18 & 91 \\
& $10^{-3}$ & 368 & 13 & 91 \\
\hline \multirow{3}{*}{ MO-PT } & $10^{-4}$ & 135 & 44 & 75 \\
& $5 \times 10^{-4}$ & 201 & 31 & 83 \\
& $10^{-3}$ & 263 & 25 & 87 \\
\hline \multirow{3}{*}{ M-PT } & $10^{-4}$ & 167 & 36 & 79 \\
& $5 \times 10^{-4}$ & 228 & 27 & 85 \\
& $10^{-3}$ & 260 & 22 & 87 \\
\hline
\end{tabular}

\section{Effect of temperature}

The effect of temperature on the inhibition efficiency was determined for mild steel in $1 \mathrm{M} \mathrm{HCl}$ containing $10^{-3} \mathrm{M}$ of different phenyltetrazole substituted compounds at different temperatures ranging from $25-55{ }^{\circ} \mathrm{C}$. The values of activation energy $E_{a}$ were calculated from the equation:

$$
i_{\text {corr }}=K \exp \left(-\frac{E_{a}}{R T}\right)
$$

where $\mathrm{i}_{\text {corr }}$ is the corrosion current density, $\mathrm{T}$ is the absolute temperature, $\mathrm{R}$ is the universal gas constant and $\mathrm{K}$ is the Arrhenius pre-exponential factor.

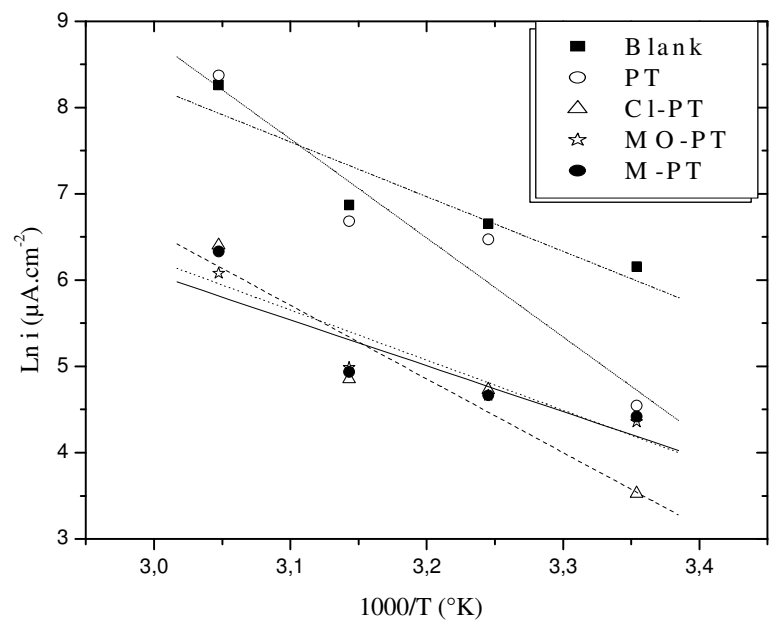

Figure 13. Relation between the corrosion rate and the reciprocal of temperature for mild steel in the presence of different concentrations of phenyltetrazole substituted compounds.

Plots of the logarithm of the corrosion rate vs. 1000/T are given in Fig. 13. The plots obtained are straight lines and the slope of each straight line gives its activation energy $E_{a}$. We note that the increase of the corrosion rate is more pronounced with the rise of temperature for blank solution. In the presence of the 
inhibitor, the corrosion rate is highly reduced at the explored temperatures for PT and slightly for other phenyltetrazole substituted compounds.

The $E_{a}$ values were found to be equal to $15,71 \mathrm{KJ} \mathrm{mol}^{-1}$ in the absence of the inhibitors and equal to $28,24 \mathrm{KJ} \mathrm{mol}^{-1}, 21,17 \mathrm{KJ} \mathrm{mol}^{-1}, 13,17 \mathrm{KJ} \mathrm{mol}^{-1}$ and 14,41 $\mathrm{KJ} \mathrm{mol}^{-1}$ in the presence of PT, Cl-PT, MO-PT and M-PT, respectively.

\section{Effect of immersion time}

Fig. 14 represents the variation of $\mathrm{C}_{\mathrm{dl}}$ for mild steel in $1 \mathrm{M} \mathrm{HCl}$ in the presence $10^{-3} \mathrm{M}$ of phenyltetrazole substituted compounds at different immersion time. Inspections of this figure reveal that the value of $\mathrm{C}_{\mathrm{dl}}$ decreases with increasing immersion time. These results indicate that the immersion time can increase the chlorides quantity which will be adsorbed on the surface helping to the formation of the inhibitor layer when the entire active sites become saturated with inhibitor. Furthermore, the change in the $\mathrm{C}_{\mathrm{dl}}$ values may be caused by the gradual replacement of water molecules by the chloride anion and by the adsorption of the organic molecules on the metal surface, decreasing the extent of dissolution reaction.

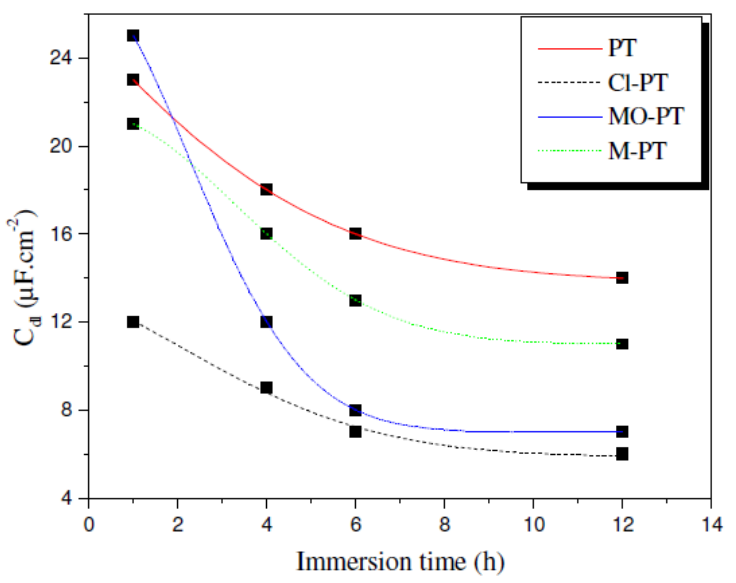

Figure 14. Change in $\mathrm{C}_{\mathrm{dl}}$ with the immersion time for the ordinary steel in the presence of optimum concentration of each compound.

\section{Adsorption isotherm}

Basic information dealing with the interaction between the inhibitor molecule and metal surface can be provided by adsorption isotherm [31]. Because the inhibition action is postulated as a result of the adsorption process, $(\theta)$ is directly related with the inhibition efficiency $\mathrm{I} E(\%)$ [32], and was calculated using Eq.(5):

$$
\theta=\frac{\operatorname{IE}(\%)}{100}
$$

We have tried to fit the coverage-concentration data to different adsorption isotherms [33], and we find that the inhibitor behavior can be best fitted to the Langmuir adsorption isotherm, which assumes that there is no interaction between the adsorbed species eventually leading to a surface saturation.

The Langmuir adsorption isotherm can be expressed as [34]: 


$$
\mathrm{KC}=\frac{\theta}{1-\theta}
$$

where $C$ is the concentration of the inhibitor, $\theta$ is the fractional surface coverage, and $K$ is the modified adsorption equilibrium constant [35,36] related to the energy of adsorption, $\Delta G$, as:

$$
\mathrm{K}=\frac{1}{\mathrm{C}_{\text {solvant }}} \exp \left(-\frac{\Delta \mathrm{G}}{\mathrm{RT}}\right)
$$

where $C_{\text {solvent }}$ is the molar concentration of the solvent, which in the case of water is $55.5 \mathrm{~mol} \mathrm{~L}^{-1}$.

The Langmuir adsorption isotherm can be rearranged to obtain the following expression:

$$
\frac{\mathrm{C}}{\theta}=\frac{1}{K}+C
$$

Hence a plot of $C / \theta$ versus $C$ should yield a straight line with intercept of $K^{-1}$. The adsorption isotherm obtained for phenyltetrazole substituted compounds is plotted in Fig. 15.

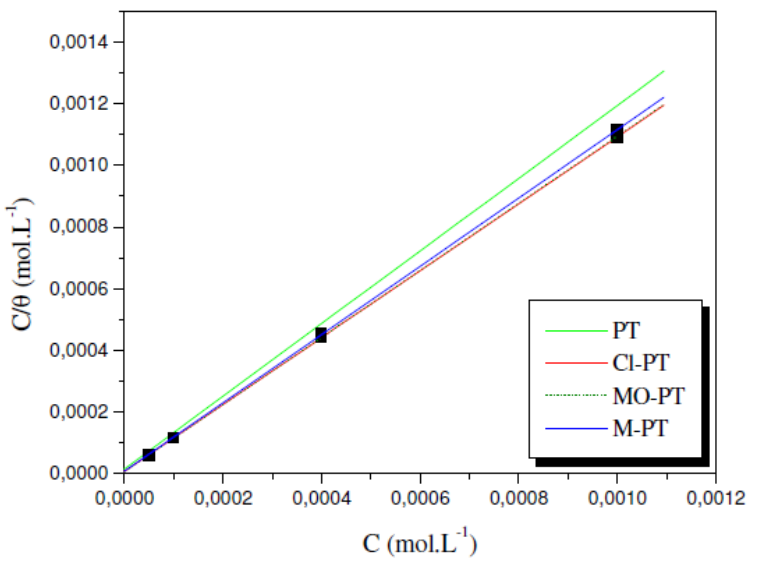

Fig. 15. Langmuir adsorption isotherm model of the mild steel surface of all inhibitors in $1 \mathrm{M} \mathrm{HCl}$.

Table 3. Slope, equilibrium constant, regression coefficient and free enthalpy of adsorption of different phenyltetrazole substituted compounds on mild steel in $1 \mathrm{M} \mathrm{HCl}$ at $298 \mathrm{~K}$.

\begin{tabular}{|c|c|c|c|c|}
\hline Compounds & Slope & $\mathbf{K}\left(\mathbf{m o l}^{\mathbf{1}}\right)$ & Regression coefficient & $\Delta \mathbf{G}_{\text {ads }}\left(\mathbf{K J . m o l}^{\mathbf{1}}\right)$ \\
\hline PT & 1,17948 & 63983.21 & 0.9999 & -37.41 \\
\hline Cl-PT & 1.0848 & 137054.83 & 0.9999 & -39.32 \\
\hline MO-PT & 1,08845 & 159115.57 & 0,99996 & -39.66 \\
\hline M-PT & 1,10878 & 128639.7 & 0,99987 & -39.14 \\
\hline
\end{tabular}

We found that all phenyltetrazole substituted compounds show a good linear fit proving that the adsorption of these compounds from $1 \mathrm{M} \mathrm{HCl}$ solution on the mild steel surface obeys the Langmuir adsorption isotherm. The equilibrium 
constant $K\left(\mathrm{~mol}^{-1}\right)$ is calculated from the intercept from which the free enthalpy of adsorption $\Delta \mathrm{G}\left(\mathrm{kJ} . \mathrm{mol}^{-1}\right)$ is obtained.

The calculated values are tabulated in Table 3 . The negative sign of free enthalpy of dsorption indicates that the adsorption of phenyltetrazole substituted compounds at steel surface is a spontaneous process.

\section{Conclusion}

All the examined phenyltetrazole substituted compounds are effective corrosion inhibitors for mild steel in $1 \mathrm{M} \mathrm{HCl}$ solution. These compounds inhibit corrosion by adsorption mechanism and their inhibition depends on the type alkyl in their structures. In added, the inhibition efficiencies increase with increasing immersion time and slightly depend on the temperature. The Cl-PT and MO-PT give the highest inhibition efficiency. The order of the inhibition efficiency of inhibitors as given by EIS measurements is in good agreement with that obtained from weight loss measurements and polarization curves. The adsorption of all compounds follows the Langmuir isotherm with negative values of free enthalpy, suggesting a spontaneous adsorption process.

\section{References}

1. S.D. Shetty, P. Shetty, H.V.S. Nayak, J. Serb. Chem. Soc. 71 (2006) 1073.

2. R. Touir, N. Dkhireche, M. Ebn Touhami, M. Sfaira, O. Senhaji, J.J. Robin, B. Boutevin, M. Cherkaoui, Mater. Chem. Phys. 122 (2010) 1.

3. E.A. Noor, A.H. Al-Moubaraki, Int. J. Electrochem. Sci. 3 (2008) 806.

4. H.P. Sachin, M.H. Moinuddin Khan, N.S. Bhujangaiah, Int. J. Electrochem. Sci. 4 (2009) 134.

5. L. Tang, X. Li, Y. Si, G. Mu, G. Liu, Mater. Chem. Phys. 95 (2006) 29.

6. S.K. Rajappa, Ph.D. Thesis, Kuvempu University, Shankaraghatta, India (2000).

7. L.B. Tang, G.N. Mu, G.H. Liu, Corros. Sci. 45 (2003) 2251.

8. F. Bentis, M. Traisnel, M. Lagrenee, Br. Corros. J. 35 (2000) 315.

9. M.A. Quaraishi, D. Jamal, Corrosion 56 (2000) 156.

10. B. Mernari, H.El. Attari, M. Traisnel, F. Bentiss, M. Lagreness, Corros. Sci. 40 (1998) 391.

11. M. Lagrenée, B. Mernari, N. Chaibi, M. Trainel, H. Vezin, F. Bentiss, Corros. Sci. 43 (2001) 951.

12. M. Elayyachy, B. Hammouti, A. El Idrissi, A. Aouniti, Port. Electrochim. Acta (2011) 57.

13. S. Martinez, I. Stern, Appl. Surf. Sci. 199 (2002) 83.

14. M. Cenoui, N. Dkhireche, O. Kassou, M. Ebn Touhami, R. Touir, A. Dermaj, N. Hajjaji, J. Mater. Environ. Sci. 1 (2010) 84.

15. K. Adardour, O. Kassou, R. Touir, M. Ebn Touhami, H. El Kafsaoui, H. Benzeid, El M. Essassi, M. Sfaira, J. Mater. Environ. Sci. 1 (2010) 129.

16. O.R. Khalifa, S.M. Abdallah, Port. Electrochim. Acta 29 (2011) 47.

17. E. Khamis, Corrosion 46 (1990) 476. 
18. I. Forsal, M. Ebn Touhami, B. Mernari, J. El Hajri, M. Filali Baba, Port. Electrochim. Acta 28 (2010) 203.

19. K. Parameswari, S. Rekha, S. Chitra, E. Kayalvizhy, Port. Electrochim. Acta 28 (2010) 189.

20. A. Alami, A. El Hallaoui, A. Elachqar, M.L. Roumestant, Ph. Vialllefont, Bull. Soc. Chim. Belg. 105, 769 (1996).

21. S. Achmlale, A. El Achqar, A. El Hallaoui, A. Alami, S. El Hajji, M.L. Roumestant, Ph. Viallefont, Phosphorus, Sulfur and Silicon 5 (1998) 1.

22. Standard practice for laboratory immersion corrosion testing of metals, $G$ 31-72, ASTM, Philadelphia, PA, (1990) 401.

23. A.D. Mercer, Test methods of corrosion inhibitors, Br. Corros. J. 20 (1985) 61.

24. A. Boukamp, Users Manual Equivalent Circuit, ver. 4.51, (1993).

25. R.H.L. Wang, R.-B. Liu, J. Xin, Corros. Sci. 46 (2004) 2455.

26. F. Mansfeld, Corrosion 36 (1981) 301.

27. F. Mansfeld, M.W. Kending, S. Tsai, Corrosion 37 (1981) 301.

28. F. Mansfeld, M.W. Kending, S. Tsai, Corrosion 38 (1982) 570.

29. F. Bentiss, M. Traisnel, M. Lagrenée, J. Applied Electrochem. 31 (2001) 41.

30. G.Y. Elewady, Int. J. Electrochem. Sci. 3 (2008) 1149.

31. M. Bouklah, B. Hammouti, M. Lagrenée, F. Bentiss, Corros. Sci. 48 (2006) 2831.

32. M. Tariq Saeed, S.K. Ali, Anticorros. Meth. Mater. 50 (2003) 436.

33. M. Ehteshamzade, T. Shahrabi, M.G. Hosseini, Appl. Surf. Sci. 252 (2006) 2949.

34. K.C. Emregul, A.A. Akay, O. Atakol, Mater. Chem. Phys. 93 (2005) 325.

35. L. Tang, X. Li, L. Li, G. Mu, G. Liu, Mater. Chem. Phys. 97 (2006) 301.

36. L. Tang, X. Li, G. Mu, L. Li, G. Liu, Appl. Surf. Sci. 252 (2006) 6394. 